\title{
A nobreza dos trópicos: uma construção através de aparências $^{1}$
}

\author{
Letícia Cunico $^{2 *}$ \\ Mara Rúbia Sant'Anna-Muller ${ }^{3 *}$
}

\section{Resumo}

Este artigo analisa algumas peças gráficas do período do governo de D. Pedro II, contextualizando-as com as características da nobreza brasileira, para apontar as relações delas com a identidade nacional construída no período.

Palavras-chaves: imagem, impressos, corte brasileira.

\section{Abstract}

This article examines some graphic parts of the period of government of D. Pedro II, contextualizing them with the characteristics of Brazilian nobility, to point the relations of them with national identity built in the period.

Key-words: image, printer, Brazilian court.

\section{Introdução}

\section{Uma nobreza de imagens}

O presente artigo se desdobra da pesquisa "Brasil por suas aparências", cujo objetivo é: "Desenvolver material historiográfico sobre a moda no Brasil, enfatizando a construção das relações de poder, a partir da aparência e suas implicações na constituição de uma identidade nacional". Dentre as diversas ações para o alcance deste objetivo geral, coube a bolsista Letícia Cunico pesquisar elementos de recorrência na produção gráfica do período imperial para que a partir deles fosse proposto um conceito visual para o ambiente virtual no qual se apresenta o conteúdo resultante da pesquisa. Tendo em vista que o mote da pesquisa, do ponto de vista teórico, é a análise das implicações da aparência na constituição de uma identidade nacional teve-se como preocupação principal apontar em que medida os elementos gráficos recorrentes no período estudado relacionavam-se com esta temática.

\footnotetext{
${ }^{1}$ Projeto de pesquisa Brasil por suas Aparências, Centro de Artes- CEART, Universidade Estadual de Santa Catarina- UDESC, orientado pela Prof. Dra. Mara Rúbia Sant'Anna, em que participam as acadêmicas Káritha Bernardo de Macedo, Letícia Cunico e Monike Meurer.

${ }^{2}$ Bolsista PIVIC. Graduanda da Universidade do Estado de Santa Catarina - UDESC, cursando Bacharelado em Moda. leticiacunico@gmail.com

${ }^{3}$ Doutora em História/UFRGS e orientadora da pesquisa "Brasil por suas aparências - uma história da moda no Brasil". Professora efetiva UDESC.
} 
Poucos trabalhos foram produzidos na literatura brasileira com este ponto de vista, sendo que os que tratam da história da tipografia e do design gráfico no Brasil - citados no decorrer deste artigo - tratam o tema de forma secundária, senão totalmente esquecida, e nisto centra-se a relevância e originalidade do estudo que se apresenta a seguir

Com a chegada da família real ao Brasil, juntamente com o Grito de Independência, o Rio de Janeiro transformou-se e à cidade foi concedida a condição de Corte. A exibição das aparências foi elemento forte de arranjos sociais e políticos no período, no qual uma nobreza nova com características peculiares buscou se construir através de imagens, mesclando tradições advindas da Europa com as particularidades dos trópicos.

Neste contexto, o presente artigo analisa algumas peças gráficas do período do governo de D. Pedro II, contextualizando-as com as características da nobreza brasileira, para apontar as relações delas com a identidade nacional construída no período.

\section{Métodos}

Como método de abordagem foi utilizado o método indutivo e como método de procedimento foi trabalhado o método de procedimento monográfico. O estudo foi construído a partir de referências bibliográficas consagradas da história do Brasil Império e da história da tipografia, litografia e design gráfico. A partir de fontes visuais, com metodologia adequada para o estudo iconográfico e iconológico, sob os preceitos de autores como Martine Joly (1996) e Pietroforte (2004), fez-se uma análise de algumas peças gráficas, disponíveis através de livros específicos, e classificadas em três grupos: rótulos; capas e brasões, os quais foram investigados a partir de três critérios: presença da figura indígena, de elementos de uma natureza tropical e do uso de arabescos, que por sua vez foram assim selecionados por terem forte relevância no discurso romântico que perpassou o projeto de nação e, logo, de identidade nacional no período imperial, tal como foi analisado no corpus principal do projeto de pesquisa de onde este texto e estudo se desdobram. Também dado a esta delimitação teórica de abordagem o período do II Império foi privilegiado e tomado como recorte temporal, especialmente em suas últimas décadas porque neste momento o projeto romântico de nação já havia sido consolidado (SANT'ANNA, 2008).

Portanto, a temática foi desenvolvida através da técnica de pesquisa de documentação indireta, envolvendo a pesquisa bibliográfica.

\section{Resultados}


Como o presente artigo não se ocupa de um trabalho de investigação quantitativa os resultados do mesmo concentram-se nas análises realizadas e sustentadas na argumentação que compõem o presente texto.

\section{Discussão}

\section{O “design" no Império}

A aplicação do termo design gráfico para o século XIX é discutível, pois consiste num anacronismo. Contudo pode-se perceber a existência de uma preocupação na diagramação de imagens e textos que refletiam os valores presentes na época e que consistiam, de uma certa forma, num trabalho de design gráfico. Segundo Lupton, desde o século XIX, o design gráfico define-se como a "manipulação e colagem de materiais existentes" (apud GRUSZYNSKI, 2000, p. 22).

Concordando com o autor pode-se então verificar que os impressos produzidos no Segundo Império, no Brasil, portavam um diferencial, provocando um impacto visual junto ao leitor e unindo a expressão estética à função de informar e comunicar. Também se destaca a força da tipografia, que tem sob o ângulo do design gráfico, o dever de transmitir uma mensagem através do desenho das letras. Este desenho deve respeitar dois aspectos a readability, ou seja, a facilidade de ler textos extensos e, legibility, que significa o rápido reconhecimento, utilizado em textos curtos como a família de tipos aplicados a logomarcas.

Stanley Morison define tipografia como:

a arte de dispor correctamente o material de imprimir de acordo com um objectivo específico o de colocar as letras, distribuir os espaços e selecionar os tipos de formas a dar ao leitor a maior ajuda na compreensão do texto. (abut McMURTRIE, 1965, p. VI)

A técnica da tipografia se estabelece no Brasil apenas em 1808 com a vinda da família Real ao Rio de Janeiro. Segundo Cláudia Marino Semeraro (1979) essa chegada tardia explica-se primeiramente pela dependência imposta pela metrópole, no sentido de manter a desinformação na colônia, sem a geração de inovações técnicas. Outro motivo pauta-se no fato do Brasil produzir apenas o que seria de interesse de Portugal, sem competir com os itens produzidos na metrópole.

Institui-se pelo decreto de 13 de maio de 1808 a Impressão Régia subordinada à Secretaria dos Negócios Estrangeiros e da Guerra e depois à Junta Diretória, responsável pela censura real. Com o tempo estes órgãos recebem diferentes denominações, finalmente atuando como Departamento da Imprensa Nacional. (SEMERARO, 1979, p. 15) 
A Impressão Régia editou impressos referentes ao governo assim como, obras científicas e literárias. Quanto aos periódicos citam-se alguns como 'Gazeta do Rio de Janeiro', 'O Patriota', 'O Bem da Ordem', o segundo destinado a temas culturais, envolvendo literatura, comércio e política. (SEMERARO, 1979, p. 16)

A partir de 1821 novas tipografias começaram a se instalarem no Rio de Janeiro, crescendo continuamente e sendo alvo de procura por estrangeiros. A partir do Rio de Janeiro outras cidades passaram a desenvolver trabalhos culturais intensos o que incentivou o surgimento de novas tipografias. São exemplos: Salvador, que desde a abertura dos portos apresentou avanços na cultura urbana, atraindo muitos comerciantes e inaugurando a difusão de jornais e revistas locais, assim como, a criação de escolas, centros culturais e indústria. $\mathrm{Na}$ Bahia e Pernamburco, financiado pelos senhores de engenho, muitos estudantes foram formados em Coimbra e quando voltavam para suas cidades natais traziam consigo o hábito da escrita e leitura, propiciando o fomento necessário para o crescimento das tipografias e materiais escritos diversos. Recife apresentava uma intensa vida cultural e, em 1816 ocorreu a instalação de sua primeira tipografia.

Como no período colonial escrever para o público sempre foi um perigo e mesmo no país já independente D. Pedro I criou um júri com o objetivo de evitar abusos e, em 1823 foi sancionada a primeira lei brasileira de Imprensa, a qual em 1830 foi reformulada para descrever com mais precisão os abusos submetidos à punição.

Se do ponto de vista cultural o fator de efervescência para a expansão do material gráfico se deve a expansão da vida urbana, também do ponto de vista tecnológico houve favorecimentos. Com a publicação de trabalho inovador de Alois Senefelder, em 1819, sobre o processo da litografia, a nova técnica disseminou-se e apresentou vantagens sobre a tipografia tradicional, possibilitando a inserção do desenho, letras e texto direto sobre a matriz, diferente das técnicas anteriores, que realizavam o processo da aplicação de imagem e texto separadamente.

A litografia chegou ao Brasil logo após estabelecer-se em países europeus como a França, Espanha e Portugal. Sua importância ganhou destaque principalmente nos impressos comerciais e publicitários. Mostrou-se um meio eficaz (de baixo custo e veloz) para a fabricação de tal material e, passou da escala reduzida para a industrial através da prensa a vapor, em uma produção dez vezes maior a partir da década de 1970.

Sem uma precisão na história da invenção da litografia a vapor, registrou-se nos Estados Unidos, segundo Rafael Cardoso (2005) mais de vinte patentes de prensa entre 1861 e 1873. No Brasil, a novidade foi apresentada em 1872 com a oficina Paulo Robin\& Cia. 


\section{Adentrando o olhar em algumas peças gráficas}

Analisando alguns dos exemplares comerciais, como capas de livros e folhetos, e publicitários, como rótulos de produtos farmacêuticos produzidos no período do Império, especialmente a partir de 1870, quando o projeto de nação proposto pelo Imperador e a ideologia dominante já estava consolidado, é possível observar a recorrência da presença de índios, elementos de uma natureza exuberante, como coqueiros, palmeiras, muitas folhagens e rios caudalosos, além de muitos arabescos que carregavam estas peças de vigor e exuberância, evidenciando a fusão dos modelos europeus com os símbolos presentes em terras tropicais.

Contudo, além de constatar a presença destes elementos é relevante interpretar estas propostas a partir do contexto e condições nas quais eram produzidas.

As imagens produzidas e consumidas no período estudado estavam sob forte influência do olhar estrangeiro, pois não havendo profissionais aptos a realizarem as atividades relacionadas à impressão e composição gráfica entre os nativos e nem quantidade suficiente para suprir a demanda do mercado de impressos, litógrafos de diferentes nacionalidades fixaram-se no Brasil a partir de 1850.

O olhar destes homens europeus, que havia se transferindo para o Brasil em busca de um sucesso profissional rápido, era carregado de uma imagem paradisíaca da terra tropical e, em geral, eles possuíam um espírito de aventura que os tinha feito atravessar o Atlântico em busca de riquezas e calor. Na Europa desde o início do século XIX foi difundido muitos desenhos sobre o Brasil, especialmente provindos dos relatos de viajantes que tanto apontavam as estranhezas de uma terra distante como pintavam com vigor suas cores. (LEITE, 1996)

Estes profissionais instalados no Rio de Janeiro, Recife ou Salvador não perderam estas inspirações e, ao contrário, incentivados por um projeto imperial de nação, ainda mais reforçavam a noção que os românticos como Gonçalves de Magalhães, José de Alencar e Carlos Gomes haviam esboçado em suas páginas, notas musicais e enredos cheios de heroísmo e dor.

O romantismo foi o caminho mais favorável à expressão própria da nação recémfundada, pois fornecia concepções que permitiam afirmar a universalidade, mas também o particularismo e, portanto, a identidade em contraste com a metrópole, mais associada à tradição clássica. O gênero vinha ao encontro, dessa maneira, do desejo de manifestar na literatura uma especificidade do jovem país, em oposição aos cânones legados pela mãe- 
pátria, sem deixar de lado a feição oficial e palaciana do movimento (SCHWARCZ, 1998, p. 128).

Num conjunto de ações do Instituto Histórico e Geográfico Brasileiro, cujo presidente de honra era o próprio Imperador D. Pedro II, e dos romancistas, que surgiram nas mais diferentes linguagens artísticas, ficou decidido que o indianismo daria conta de construir o passado heróico e puro, como a obra de Gonçalves de Magalhães A Confederação dos Tamoios soube fazer com primor. Nesse romance, num passado distante, heróis indígenas prevêem um futuro de glória a terra da Santa Cruz pelas mãos de um imperador sábio e justo.

Também as obras $O$ Guarani e Iracema de José de Alencar têm seu valor neste contexto, apesar do autor se colocar como opositor do imperador e dos literários que faziam parte de sua intimidade. Alencar defendia que apenas ele propunha um passado real à Nação brasileira, no qual seus índios e seus portugueses relacionavam-se de maneira perfeita e redentora da nova nação, sendo a natureza e seus habitantes descritos com rigor geográfico e etnográfico, tornando esta descrição uma certidão de nascimento da nação brasileira. $\mathrm{O}$ enredo dos romances, tal como um mito fundante, explica a origem e o destino da Nação. (ORTIZ, 1987)

Gonçalves Dias, gozando do apoio de D. Pedro II, também compôs poemas que ajudaram a construir os indígenas brasileiros como heróis semelhantes aos cavalheiros medievais europeus ou parecidos com os bravos guerreiros de Roma e da Grécia Antiga.

Também nesse processo de composição de um passado inaugural de uma Nação, a ópera de Carlos Gomes, O Guarani, criada a partir do romance de Alencar, fez um papel de grande relevância. Em 1870, ela estreou no Scala de Milão, financiada por D. Pedro II. Esse trabalho monumental combinava as normas européias com o objetivo de exprimir os aspectos ditos mais originais da cultura brasileira. A ópera apresentava toda a composição musical seguindo as regras românticas, porém tendo como base a musicalidade indígena. Os cenários criados com maestria e eternizados na aquarela de Carlo Ferrario, combinados com o figurino suntuoso, que mais se aproximava de clâmides e saiotes romanos do que Dos trajes indígenas do período colonial, faziam da ópera um grande espetáculo onde se via uma identidade exaltada como única, mas, ao mesmo tempo, apresentada como universal porque semelhante em seu heroísmo e teor épico à origem romântica de qualquer Nação européia.

Para a elite brasileira que tinha acesso às revistas e jornais que circulavam no Brasil, dando notícia do sucesso que a ópera de Carlos Gomes alcançara na Europa, a memória de um passado heróico e também épico foi se cristalizando. As lições de história nacional, ministradas nos colégios que os filhos da elite freqüentavam, firmavam-se em documentos históricos, como a Carta de Caminha, para reafirmar uma ficção romântica que, cada vez 
mais, foi descontextualizada do seu lado literário, para tornar-se uma "testemunha" do passado.

Assim sendo, os desenhistas, tipográficos, litógrafos ou quem trabalhasse com o material gráfico na época imperial estava influenciado por esta forma de expressar o Brasil: a pátria de indígenas corajosos e vigorosos, porém pacíficos e sábios, ao lado de uma natureza que transformada pela civilização fazia a diferença sem rebaixar o país a uma selva indomável.

Quanto maior foi a mecanização dos impressos visuais, principalmente a partir de 1850 a 1890, muito mais fácil ficou a circulação de imagens caracterizadas pelo desenho e impressa através da litografia.

\section{Observando capas}

O período de 1850 até 1890 é marcado pela utilização de tipos ornamentais, rebuscados e decorados. Isso se explica tanto pelos aspectos técnicos desenvolvidos como pela caracterização da idéia de progresso e a civilidade realizada por meio da abundância de materiais, segundo Cardoso (2005) confirmando a argumentação anterior, o que explica a presença de uma variedade de famílias tipográficas em um mesmo impresso, como no exemplo de A Saudade (ANEXO A).

Neste exemplo observa-se o grande destaque dado ao título com tipos ornamentados, que delimitam a ilustração de uma harpa em meio a arbustos. Percebe-se o forte emprego de letras maiúsculas na época. No trecho Publicação Litteraria e Instructiva vê-se o emprego de letra com serifa, acabamento nas terminações das hastes, sua origem remete-se aos caracteres romanos. Abaixo se encontra o emprego da tipografia tridimensional, outro elemento explorado na época. Demonstrando os vínculos com o período imperial verifica-se a presença do brasão e o nome da tipografia abaixo.

Na capa de Viagem Pitoresca a Petrópolis (ANEXO B), percebe-se elementos decorativos inspirados nas formas greco-romanas na moldura da capa, influência do movimento neoclássico pautado na arquitetura e nas artes decorativas, o que se relaciona ao romantismo - não como escola artística, mas como ideologia de uma época - devido a valorização do passado, sempre visto como tempos áureos. A variedade de famílias tipográficas também está presente, destacando a palavra principal do título, Petrópolis. A capa segue um padrão que pode ser percebido na época, o título, informações, ilustração, cidade, tipografia e ano. 
Também é relevante destacar que o tema do livro se relaciona diretamente à realeza, pois Petrópolis - a cidade de Pedro - era a escolhida pelo Imperador como refúgio privilegiado da vida da Corte e que por seu clima e população de origem alemã, predominantemente, aproximava a monarquia brasileira dos hábitos e costumes das monarquias estrangeiras. Desta forma, o uso dos tipos neoclássicos remete a esta relação implícita entre a civilização européia, clássica e berço da civilização ocidental com a brasileira.

Outra capa interessante de ser analisada é a do livro Um casamento no Arrabalde (ANEXO C). Nesta também continua presente a moldura, todavia o mais interessante é a ilustração central composta por desenhos da fauna e da flora brasileira. Mais uma vez a escolha gráfica se associa ao tema do livro, pois os arrabaldes - subúrbio, cercanias de uma população - (FERREIRA, 2005, p. 111) era nesta época sinônimo de região rica em natureza e bucólica, como o romantismo pintava, fazendo com que as pessoas estivessem mais próximas de uma natureza boa e saudável a sua alma. Num Brasil que se gabava de possuir em excesso este refúgio por excelência da alma nada melhor do que enfatizá-lo colocando na capa exemplares desta exuberância local.

Nesta capa ainda se destaca um elemento novo: o nome do autor exibido com letra cursiva lembrando uma assinatura.

\section{Observando Rótulos}

A influência do olhar estrangeiro está expressa também nos mais diferentes rótulos. Já naquela época tinha-se noção que a elaboração acurada de um bom rótulo ou etiqueta comercial fazia vender melhor o produto. O rótulo, portanto, devia ser colorido, bem desenhado e deixar evidente duas coisas, principalmente: a chancela que o fabricante dava ao produto, fazendo com que o seu nome aparecesse em destaque e, em segundo, que permitisse pelas ilustrações dar a entender suas atribuições e qualidades. Afinal a alfabetização era produto de luxo e seriam estes desenhos e o impacto visual do rótulo que facilitaria o reconhecimento e avaliação do produto.

Um exemplo muito rico deste período é a etiqueta do Xarope d'Abacachi (ANEXO D). A ilustração expõe uma índia coberta por drapejados clássicos e ornada com acessórios metálicos o que se contrapõe com o cocar e o instrumento de caça que também foram desenhados junto à figura. Ao olhar o desenho feminino se identifica claramente se tratar de 
uma índia, porém não uma índia selvagem e indomada, má nutrida ou ignorante. O quíton que porta a assemelha a uma deusa mítica, talvez Pala-Athena, e desta forma a sabedoria, a civilidade e a tradição dos tempos da velha Grécia se associam a esta figura e torna-se muito coerente ao projeto de nação do Império.

Ela ainda está inserida em uma paisagem que segue esta mesma fusão da civilização antiga e enobrecedora com a exuberância e força das terras brasileiras. Foi desenhada a índia grega em meio a uma floresta de abacaxis - matéria-prima do produto, não deixando margem de engano ao seu consumidor - com um barco e um farol ao lado, representando a colonização ou a civilidade que teria industrializado, aperfeiçoado e permitido o consumo e eficiência do conhecimento local dos poderes terapêuticos do abacaxi. A figura da índia apóia-se em um escudo, o qual possui um brasão desenhado, remetendo, neste caso à firma que produz o xarope e sua tradição e renome como empresa farmacêutica idônea. Na parte superior do rótulo encontram-se desenhado algumas medalhas, o que indica as premiações que o produto recebeu em exposições industriais na qual participou.

Neste rótulo, como na maior parte deles, não há uma moldura tão fechada como se observa nas capas dos livros, proporcionando assim uma maior liberdade na combinação de texto e imagem, sem uma limitação final. Destaque também à possibilidade de modificação dos textos para idiomas diferentes, técnica proporcionada pela litografia.

Ao lado do rótulo do Xarope d'Abacachi, numa mesma proposta discursiva, pode-se colocar o rótulo de fumo Ramon Anido (ANEXO E).

Neste se observa também a representação do corpo e da pose da índia nos moldes da figuração do corpo humano segundo repertório clássico acadêmico. Em uma idealização do movimento romântico brasileiro ela apresenta-se com o cocar, arco, flecha, penas e adornos, porém seu corpo e postura fazem alusão direta às imagens clássicas das deusas gregas. Esta figura está em um ambiente de natureza e, em suas mãos segura um galho de planta de fumo. Observa-se neste exemplo a questão das molduras, de forte presença nas capas de livros como citado anteriormente. Uma decoração que lembra a arquitetura neoclássica e, que remete também as exuberâncias naturais dos trópicos.

Os termos deste rótulo são escritos em estilos típicos da época, segundo Rafael Cardoso (2005), como o toscano (Superior Fumo de Minas, Importado do Rio de Janeiro e Garantido por Especialidade e Rio de Janeiro), o semi-serifa (Ramon Anildo e textos 
laterais) e o tridimensional (Artigas) com contorno acentuado e sombreamento branco. $\mathrm{O}$ nome do fabricante recebia destaque em sua localização e utilização do tipo diferenciado, fazendo com que ele fosse reconhecido com facilidade em meio a tantas outras informações. Constava também o endereço de mesmo.

Na preocupação com a diagramação do rótulo, perceber-se a questão da simetria e do equilíbrio, valorizado na época, com duas mensagens em forma de carta, uma em cada lado da ilustração da índia. No lado esquerdo exaltando as qualidades do produto e atestando a garantia do mesmo e, no lado direito especificando o produto e sua origem. Os arabescos dão evidencia a palavra Especialidade e a fábrica.

A simetria aparece também no rótulo da Imperial Fábrica de S. João de Nictheroy (ANEXO F) onde o número 63 do endereço aparece duplicado, característica do estilo neoclássico.

Como os demais, este rótulo descreve o momento da sociedade da época e o projeto de identidade nacional defendido. Percebe-se, em primeiro plano, a cena da natureza com um índio, à esquerda, carregando sua caça exótica e abundante, sinal da fartura das terras brasileiras. Na outra mão foi desenhado um arco, na cabeça um cocar e ainda um colar de penas. Se tudo indica um índio bem brasileiro, seu corpo o afasta dos silvícolas reais. Seu corpo, desenhado robusto, forte e valente, se aproximava do ideal europeu, lembrava Emílio de J-J. Rousseau - o bom selvagem que veste um drapejado à moda clássica. Também a companheira deste índio cheio de galhardia, desenhada à direita do rótulo, sugere alguma musa clássica e usa colar e sandálias que lembram influências gregas. Em uma pose relaxada, recostada na janela da composição, a índia fuma um cigarro. O cachorro, ao seu lado, desliga a cena da noção de floresta e a aproxima do ambiente doméstico, exemplificando a domesticação que ocorreu não apenas com os animais. A índia tal como o cão são “civilizados" e em seus arranjos no rótulo representam a aceitação dos costumes europeus. Para o caso de um rótulo de fumo isto é muito significado, pois sabe-se que o hábito de fumar foi introduzido na Europa após as descobertas marítimas, tendo sido copiado dos costumes indígenas americanos, portanto, mostrar uma índia a pitar faz alusão a origem deste hábito, contudo mostrando-a domesticada e semelhante às musas antigas conota o consumo do fumo como algo compatível à civilização. 
Entre as duas figuras indígenas foram sublinhados olhares que demonstram um jogo de sedução. Na janela oval ${ }^{4}$ que se abre no centro do rótulo encontra-se a fábrica, símbolo de progresso, com uma grande chaminé, larga construção e pavimentação. Situando mais uma vez a civilidade, a fábrica representa o progresso e a combinação perfeita entre a natureza, com seus produtos e desejos, e o trabalho humano branco e europeu, engenhoso e transformador. A janela trabalha como um elemento de aproximação entre o casal indígena, onde a civilidade torna-se um espaço de reencontro, transformação e mesmo salvação da barbárie.

Ainda o rótulo traz elementos como as medalhas de premiação, o brasão imperial e no nome do produto, cujo termo Imperial expressa a associação da fábrica ao Imperador.

Os rótulos eram um meio de disseminação de idéias em uma sociedade em que predominava o analfabetismo.

\section{Observando Brasões}

Outro elemento que deixa transparecer as características da sociedade da época é os brasões. Uma prática que teve como base, segundo Lilia Schwarcz (1998), os valores da cavalaria, passando depois a símbolos de família e grupos. A escolha dos motivos gráficos gravados nos brasões ficava por conta do proprietário e deveriam transmitir as qualidades que o diferenciava dos demais membros da corte e das pessoas comuns.

Como forma de controlar as informações difundidas, os brasões passavam pelas mãos dos Estados reais, os quais controlavam, autentificavam e ordenavam esta arte. E, para a aquisição da carta de brasões pagava-se um imposto do selo. Porém como cita Lilia Schwarcz (1998, p. 181): “Ao que tudo indica, ostentar o título em situações públicas e tê-lo impresso em algum jornal local era mérito suficiente e significava muito diante das grandes despesas da confecção de um brasão."

Os desenhos externos dos brasões, como a coroa, simbolizavam uma hierarquia, como no Brasão de Antonina (ANEXO G), onde a coroa significa o título de conde do proprietário.

Já o desenho interno correspondia aos predicados e glórias que a família proprietária do brasão possui, construindo uma narrativa heróica e nem sempre verdadeira dos feitos hereditários. Se na Europa a tradição heráldica se baseava nos tempos medievais e em grandes conquistas e batalhas, utilizando com fartura símbolos mimetizados, devido a distância

\footnotetext{
${ }^{4}$ Janela oval: termo utilizado por Rafael Cardoso (2005) para destacar o espaço utilizado por outro desenho - da fábrica - que contrasta com o ambiente da natureza, no caso específico desta ilustração.
} 
temporal e a tradição que permitia isso, no Brasil honrando para ser honrado, os nobres de espada, ou seja, aqueles que recebiam os títulos nobiliárquicos por uma graça do Imperador, esforçavam-se em reafirmar o projeto de nação que a nobreza defendia, fazendo de seus brasões também uma narrativa da nação, onde se coadunavam a natureza e a riqueza estonteante aos feitos de civilização e progresso.

No Brasão de Antonina observam-se símbolos tipicamente brasileiros: o índio com seus adornos como o cocar e o arco. Ao seu lado, de maneira estilizada, um "leão em rompante, representado de perfil e com a cauda levantada, símbolo de coragem e comando" (SCHWARCZ, 1998, p.168) e, em suas garras um catecismo e um rosário, como se estivesse apresentando-o ao nativo e fazendo alusão ao trabalho de desbravamento e cristianização que a família realizou junto aos nativos e à terra. Um gesto que representa a civilidade e a catequização trazida pelo europeu para as terras tropicais, no intuito de introduzir no indígena os valores cristãos cultuados pelo colonizador.

No Brasão de Japaratuba (ANEXO H), a coroa em destaque representa o título de barão. Visualiza-se outros elementos também, como a cana-de-açúcar, simbolizando uma fonte de riqueza e no quadrante a direita uma construção ostentosa. Ainda aparece um leopardo na representação da fauna local, distanciando-se dos animais criados pelo imaginário europeu e, no quadrante oposto um índio com um galho de café na mão direita e na esquerda, flechas. Para driblar a quase impossibilidade da impressão em cores, na época, utilizou-se da representação gráfica para tal. No exemplo do brasão abordado, vê-se o amarelo (em pontilhados), azul (com traços horizontais) e vermelho (traços verticais).

Um item a verificar-se nesta Corte é a utilização de nomes de origens guaranis para denominar os títulos de nobreza como acontece com o Barão de Japaratuba, citado acima. Através dessa denominação percebia-se a influência que os trópicos exerciam sob a Corte local, a qual projeto de nação essa estratégia servia, reafirmando a identidade pela a vontade de se diferenciar se assemelhando à nobreza Européia onde termos muito próprios do velho continente atribuíam a denominação dos títulos nobiliárquicos (Ver DAMATTA, 1986) .

Como último exemplo gráfico aborda-se o Brasão do Barão de Rio Negro (ANEXO I), onde se apresenta uma divisão em cruz e, no primeiro e no quarto quadrante estão três cabeças de índio, com cocar e um adorno na orelha, em um fundo dourado, representado graficamente por pontilhados. No segundo e quarto quadrante está um pelicano em seu ninho, nutrindo seus filhotes com o fundo vermelho (linhas verticais). Outra característica presente nos brasões são as faixas com uma mensagem abaixo da representação. Estas legendas quase sempre escritas em latim e as imagens de natureza e ação humana sobre esta ou da presença 
da religião reafirmam o ideário de construção de um Império nos trópicos que nada deixasse a desejar aos demais impérios centenários.

Observa-se que raramente encontra-se na arte heráldica a representação da figura do negro, o que indica, mais uma vez, que não constava do projeto de identidade nacional proposta pelo Segundo Império brasileiro a mancha da escravidão, um sinal da distância com a industrialização que já se produzia a plenos vapor na Europa e nos Estados Unidos da América e com o próprio Iluminismo e Liberalismo, corrente filosóficas e políticas que sustentavam as sociedades burguesas do século XIX..

De características peculiares, a nobreza brasileira representou em elementos como o brasão uma imagem pretendida, a qual mesclava características européias, com símbolos tropicais, via-se em seu espelho construído como uma sociedade civilizada, tradicional tendendo para o moderno, rica, cristã e catequizadora, sem ser, na imagem construída, escravocrata.

A não-hereditariedade dava a esta nobreza um caráter singular, os títulos eram concedidos devido a méritos pessoais, conquistas ou por compensação política e econômica, em uma ausência de leis que regulamentassem tal ato. Vingava-se então uma nobreza de títulos passageiros e, assim como afirma Lilia M. Schwarcz (1998), a hereditariedade existia apenas na família imperial.

\section{Conclusão}

O objetivo deste texto e da pesquisa que o ensejou obteve êxito, pois facilmente se identificou nos exemplares selecionados, nos três segmentos definidos previamente, a reafirmação do projeto de identidade nacional presente no Segundo Império Brasileiro. Através dos recursos gráficos como a tipografia, desenhos, alegorias e mesmo palavras ficou evidente a proposta narrativa de uma nação que romanticamente se via como civilizada porque capaz de domar sua exuberante natureza e população selvagem. Numa combinação recorrente ao lado de figuras indígenas, lembrando deuses gregos e a tradição clássica, se viu exemplares da fauna e flora típicas dos trópicos, os quais sempre estavam associados à ação humana realizada pelo homem de origem européia que tudo transformava com seu espírito empreendedor e civilizatório.

A partir deste estudo pode-se, portanto, compor um ambiente virtual que corresponda à norma estética que prevaleceu no design gráfico do $2^{\circ}$. Império e oferecer, assim, ao usuário 
do mesmo uma performance mais otimizada de compreensão e emersão nos conteúdos tratados pelo projeto de pesquisa "Brasil por suas aparências - volume 2". 


\section{Anexos}

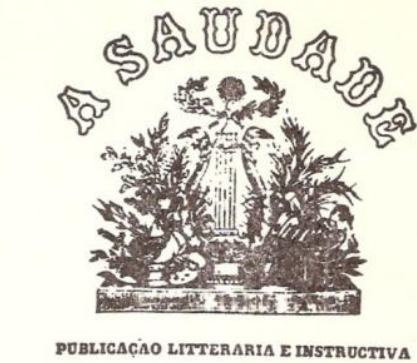

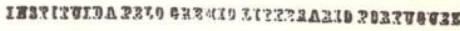

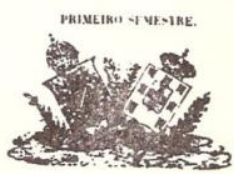

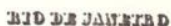

THPOGAPRAS DE FORTCX.ATO ANTONIO DE AI.MEIDS

MTIDTILIY, III.

18:36

ANEXO A

'A Saudade', Rio de Janeiro RJ, Typografia Clássica de F.A. de Almeida 1856-1857, semanário, 25,5x16cm. Publicado pelo Grêmio Literário Português. Ao todo saíram 76 números. (AR).

Fonte: História da Tipografia no Brasil. História da Tipografia no Brasil. Museu de Arte de São Paulo. Secretaria de Cultura, Ciência e Tecnologia do Governo do Estado de São Paulo, p. 88.

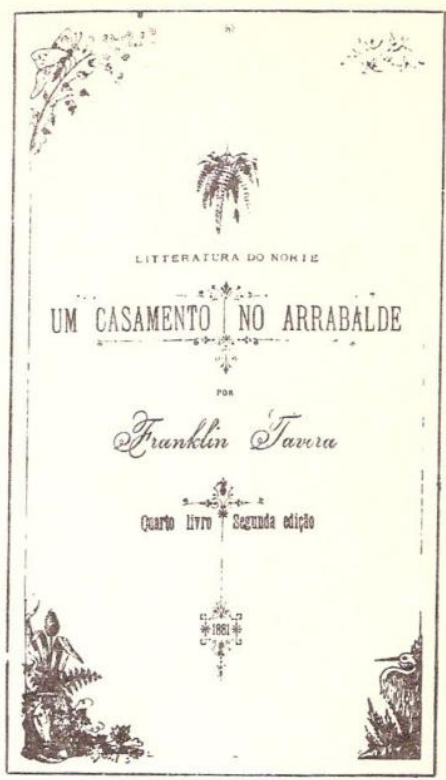

\section{ANEXO C}

Távora, João Franklin da Silveira (CE 1842 - RJ 1888). Bacharel em direito pela faculdade do Recife, exerceu os cargos de: diretor geral da Instrução Pública, deputado da Assembléia Provincial, secretário da presidência do Pará. Literado e fundador da Associação de Homens de Letras. Rio de Janeiro RJ, Typografia Nacional, VI, 102 pp., $15 \times 22 \mathrm{~cm}, 500$ ex. (JM).

FonteHistória da Tipografia no Brasil. Museu de Arte de São Paulo. Secretaria de Cultura, Ciência e Tecnologia do Governo do Estado de São Paulo, p. 122.

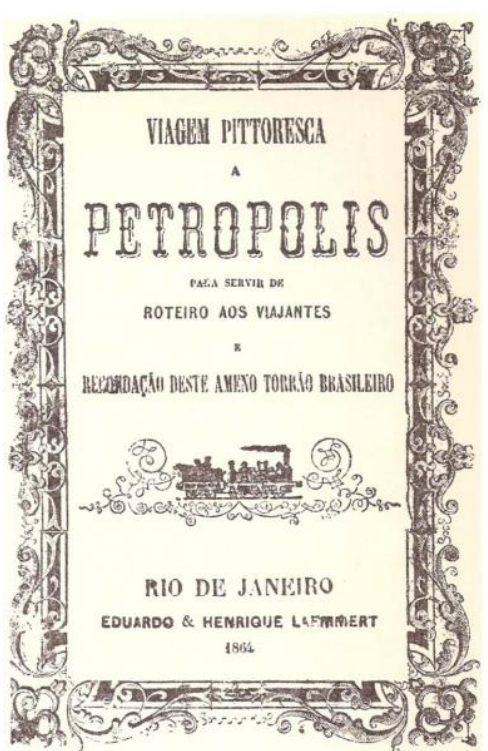

ANEXO B

[Taunay, Auguste Marie Charles] (França 1791 - RJ 1867). Veio para o Brasil juntamente com outros nomes importante, a convite de D. João Vi. Serviu no exército francês como major. Escreveu vários artigos no peródico 'Rverbero Constitucional'. Vig. 144 pp., $16 \times 11 \mathrm{~cm} .(\mathrm{JM})$.

Fonte: História da Tipografia no Brasil. Museu de Arte de São Paulo. Secretaria de Cultura, Ciência e Tecnologia do Governo do Estado de São Paulo, p. 103.

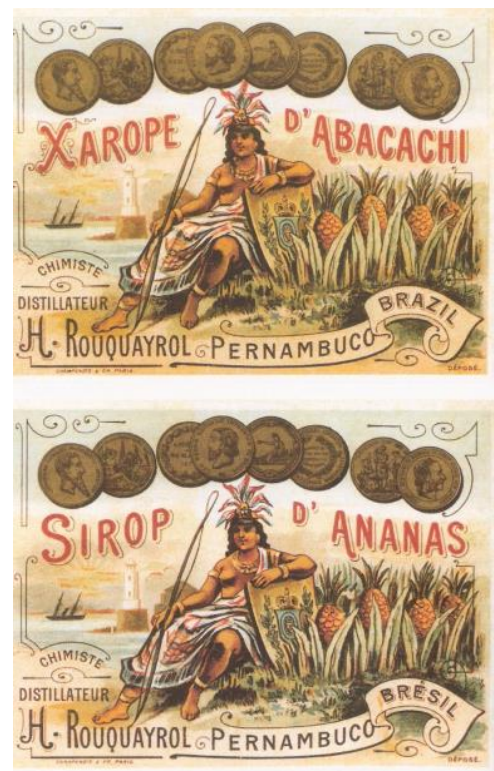

ANEXO D

CARDOSO, Rafael. O design brasileiro antes do design, 18701960, p. 34

Fonte: A circulação de imagens no Brasil oitocentista, Arquivo Nacional. 


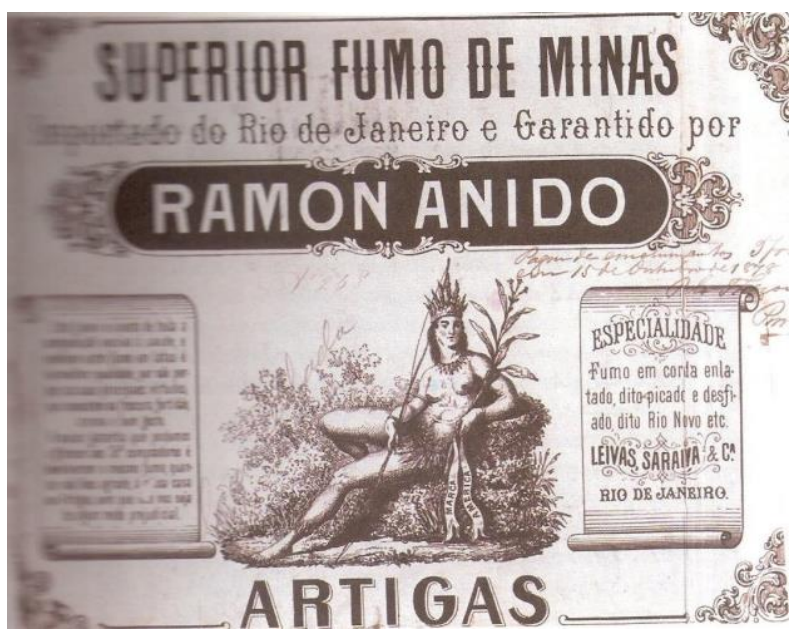

\section{ANEXO E}

CARDOSO, Rafael. O design brasileiro antes do design, 18701960, p. 35.

Fonte: A circulação de imagens no Brasil oitocentista, Arquivo Nacional.

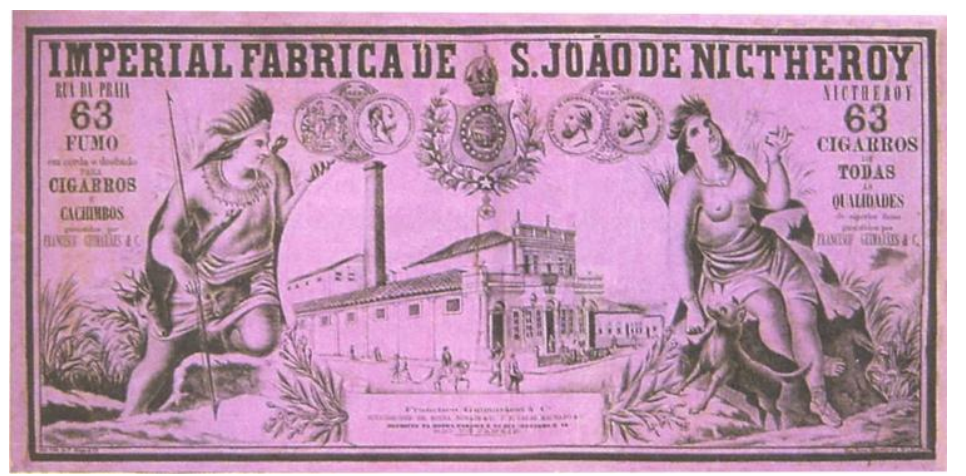

ANEXO F

CARDOSO, Rafael. O design brasileiro antes do design, 18701960, p. 47.

Fonte: A circulação de imagens no Brasil oitocentista, Arquivo Nacional.

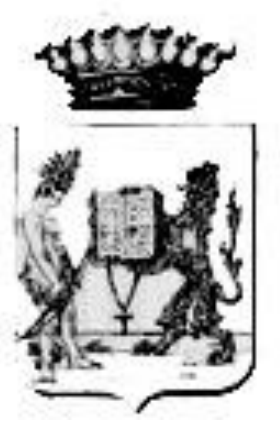

ANEXO G

Brasão de Antonina

Fonte: SCHWARCZ, Lilia

Moritz. As barbas do Imperador:

D. Pedro II, um monarca nos trópicos. P. 186.

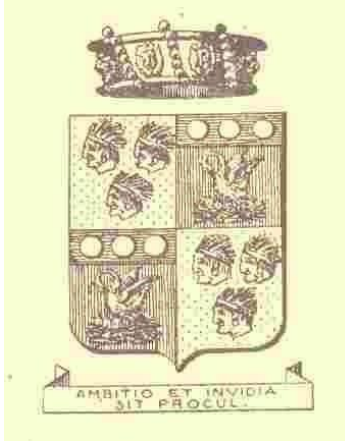

ANEXO H

Brasão de Japaratuba

Fonte: SCHWARCZ, Lilia

Moritz. As barbas do Imperador:

D. Pedro II, um monarca nos trópicos. P. 186.

\section{ANEXO I}

Brasão do Rio Negro Fonte: SCHWARCZ, Lilia Moritz. As barbas do Imperador: D. Pedro II, um monarca nos trópicos. P. 186. 


\section{Referências bibliográficas}

CARDOSO, Rafael. O design brasileiro antes do design, 1870-1960. São Paulo: Cosaz Niafy. 2005.

DAMATTA, Roberto A. O que faz o Brasil, Brasil? Rio de Janeiro: Rocco, 1986.

GRUSZNSKI, Ana Cláudia. Design Gráfico: do invisível ao ilegível. Rio de Janeiro: 2AB. 2000.

História da Tipografia no Brasil. Museu de Arte de São Paulo. Secretaria de Cultura, Ciência e Tecnologia do Governo do Estado de São Paulo. 1979.

JOLY, Martine. Introdução à análise de imagem. Campinas: Papirus., 1996.

LEITE, Ilka Boaventura. Antropologia da Viagem. Belo Horizonte: Editora UFMG, 1996.

McMURRIE, Douglas. O Livro. Eighth Priting. 1965. New York: Oxford University Press, Inc. Tradução de Maria Luísa Saavedra Machado. Lisboa: Fundação Calouste Gulbenkian. $2^{\mathrm{a}}$ ed.

NIEMEYER, Lucy. Tipografia: uma apresentação. Rio de Janeiro: 2AB. 2003. 100p.

ORTIZ, Renato. Românticos e Folcloristas. Rio de Janeiro: Rocco, 1987.

PEREIRA, Aldemar d'Abreu. Tipos: desenho e utilização de letras no projeto gráfico. Rio de Janeiro: Quartet. 2004.

PIETROFORTE, Antonio Vicente. Semiótica visual - os percursos do olhar. São Paulo: Contexto, 2004.

SANT'ANNA, Mara Rúbia. Império - uma civilização nos trópicos. In: Brasil por suas aparências - volume 2. Florianópolis: UDESC, 2008. [Cd-rom].

SCHWARCZ, Lilia Moritz. As barbas do Imperador: D. Pedro II, um monarca nos trópicos. São Paulo: Companhia das Letras. Ed. Schwarcz Ltda. 1998. 